SWEDEN

\title{
Making sense of senselessness
}

As progress falters in the drawn-out second round of the Strategic Arms Limitation Talks (SALT), concern is also growing about the implications of large-scale environmental warfare. But popular attention is often diverted away from both the true state of present technological developments and the strategically valueless damage which the military use of existing techniques has already done. From Stockholm, Wendy Barnaby reports.

WHEN two such prestigious organisations as the Royal Swedish Academy of Science and the Stockholm International Peace Research Institute (SIPRI) collaborate to produce a public statement on a topical issue, it is not surprising that it should attract a lot of publicity. But press reports of their predictions about war and the environment, which are contained in the latest edition of the Academy's journal Ambio, have generally been both inaccurate and misleading.

The journal describes the damage done to the biosphere by war, and the ways in which natural environment phenomena could be manipulated for belligerent purposes. It also discusses some of the international negotiations to draw up treaties prohibiting modification of ecological systems for hostile ends. Most of the publicity surrounding the issue has concentrated on articles which document the worldwide spread of all types of sophisticated weapons, describe the likely results of a nuclear war in Europe, and catalogue the possibilities of weather manipulation.

Press accounts of the prospects for environmental warfare have dwelt on seeding clouds, modifying hurricanes, oceans, earthquakes and climates, and tampering with the ozone layer, without mentioning what Ambio stresses: that the techniques for doing these things involve many practical difficulties and are at the moment "theoretical and speculative" only. Geophysical modification as a weapon system is certainly not just around the corner, but the presumption is that the public has the right to know which stage in the sequence has bcen reached: a fait accompli is harder to oppose than something not yet completed.

The global proliferation of modern conventional weapons suggests that more attention might be paid to the damage they can cause. Dr Malvern Lumsden. a Research Fellow at SIPRI, describes the impact of strategic bombing in the Second World War, for example of Berlin, and of the bombing of South Vietnam by the United States. He concludes that the level of social organisation (which is different from the level of "development") of the bombed population is the prime determinant of its ability to withstand environmental stress. This conclusion is interesting in the context of the environmental stress that urban guerillas seek to inflict through the use of terror-a topic on which the journal might have shed some light by considering which factors most often influence the outcomes of sustained campaigns of kidnapping, hijacking and attacks against embassies.

Apart from anticipating future weapon systems, the press could also publicise the extent of the damage caused by those presently deployed. In another article, a former US marine officer, Professor Arthur Westing, describes the three prongs of American tactics in South Vietnam between 1965 and 1973. Professor Westing, presently a botanist who visited SIPRI as a researcher in 1975, details the effects on the country's ecology of high explosive munitions, herbicides and land-clearing tractors ("Rome ploughs"): the instruments used by the USA to make the land inhospitable to enemy guerillas. One quarter of the land area of the entire country was covered by B-52 crater fields alone. One tenth of the land area-about 1.7 million hectareswas sprayed once or more with herbicides. And about $2 \%$ of the land area was cleared by Rome ploughs, 33,000$\mathrm{kg}$ armoured tractors whose blades can split and topple trees of almost any size. These destructive techniques proved to be of only doubtful military value, but Professor Westing forecasts that future combatants will intensify their use in order to raise their military pay-off. The result will be even more desolation than was caused in South Vietnam.

Destruction on the scale implied by present levels of armaments can, of course, only be supported by enormous resources. Another SIPRI Research Fellow, Ronald H. Huisken, calculates that world military expenditure totalled $\$ 210.300$ million in 1974 , and that the raw materials used for global military purposes are at present worth about $\$ 250.000$ million-the equivalent of the combined gross national products of the 65 countries of Latin America and Africa. That natural resources are used to desecrate the environment in which they were formed represents just one of the many ironies characterising the present ridiculous levels of militarisation.

\section{CERN \\ II on target}

The Geneva-based European Organisation for Nuclear Research (CERN), in which 12 European governments participate in a collaborative programme of subnuclear physics research, largely through teams of visiting scientists, has two particle accelerators that have been operational for many years. Peter Collins reports on the super proton synchrotron (SPS) now under construction

THE meeting of the CERN Council just before Christmas marked the end of an era with the retirement of Professor W. Jentschke following his five-year term as Director General of CERN I, the original CERN laboratory. Since January 1 of this year the two CERN laboratories-CERN I and the one to house the SPS, CERN II-have been combined. Instead of two separate Directors General, the whole complex has two men working side by side: Dr J. B. Adams, as Executive Director General, is responsible for everything concerned with management, while Professor L. van Hove of Belgium fills the new appointment of Director General responsible for research.

Interest at CERN inevitably centres, however, on the $400-\mathrm{GeV}$ SPS. Unlike many (and perhaps most) such building projects, its construction is moving ahead on schedule and within its estimated budget. The last of 744 bending magnets in the $6.9-\mathrm{km}$ ring was installed a month or so ago to coincide with the meeting of the CERN Council. According to Dr Adams, who was the Director General of CERN II, there have been few serious problems during constructicn of the new machine.

Apart from the apparently inevitable delays arising from late delivery of components, only one major difficulty seems to have arisen. This was the discovery, early in 1975, of serious deterioration in the insulation of a number of the magnets that had already been installed. Urgent and intensive detective work showed that the failure was always in the same area of the coils; it was found to be caused by the use, on the ends of cables, of a cleaning fluid that contained a high proportion of phosphoric acid. Where this had not been completely cleaned off, the acid attacked the resin used for insulation, and had the effect of continuing its "curing". The result was that the resin hardened, shrank, and eventually cracked, allowing the acid to get through into the glass cloth used for the inner insulation, and thence to the 